\title{
A Patient with Graves' Disease who Developed Hypothyroidism Associated with Thyroid Stimulation Blocking Immunoglobulin during Anti-thyroid Drug Therapy
}

\author{
Hiroaki INOMATA, ToshiYUKi TSUYUSAKI*, Nozomu SASAKI**, \\ KiYoe TAMARU**, Hiroo NIIMI** and Hironori NAKAJIMA** \\ Department of Pediatrics, Ichihara Hospital, Teikyo University \\ School of Medicine, Chiba 299-01 Japan \\ * Department of Pediatrics, Narutou Hospital, Chiba 289-13 Japan \\ ** Department of Pediatrics, Chiba University School of Medicine, Chiba 280 Japan
}

\begin{abstract}
A girl, 12 years of age, developed Graves' disease compounded with rheumatic fever and idiopathic thrombocytopenic purpura. Thrombocytopenia improved under short-term treatment with steroids and her mitral valvular insufficiency, due to the rheumatic fever, disappeared 4 years later. Initially, she had been treated with propylthiouracil (PTU) for 28 months. She suffered a relapse 9 months after stopping PTU and so she was given further PTU therapy. However, hypothyroidism developed 11 months after the initiation of therapy and continued, though further PTU treatment was discontinued. She now receives 1-thyroxine and maintains a euthyroid state.

At the onset of the patient's hyperthyroidism, the TSH-binding inhibitor immunoglobulin (TBII) and the thyroid stimulating antibodies (TSAb) were found to be positive. During the remission period, only the thyroid stimulation blocking immunoglobulin (TSBI) was weakly positive. At relapse, only TBII was mildly positive. When hypothyroidism developed, both TBII and TSBI were positive, and TSAb was negative in all testings of her diluted IgGs.

The patient's TBII and thyroid dysfunction were unaffected by high-dose intravenous gammaglobulin therapy or by treatment with prednisolone 0.5 $\mathrm{mg} / \mathrm{kg} /$ day for 2 weeks.

In conclusion, the emergence of TSBI during or after anti-thyroid drug therapy might possibly lead to hypothyroidism in patients with Graves' disease.
\end{abstract}

A TSH binding inhibitor immunoglobulin (TBII) and a thyroid stimulating immunoglobulin (TSAb) have been observed in many patients with Graves' disease (Smith and Hall, 1974; McKenzie et al., 1976). In another finding, TBII and a thyroid stimula-

Received September 24, 1987 tion blocking immunoglobulin (TSBI) have been observed in some patients with primary myxedema (Endo et al., 1978; Konishi et al., 1983; Arikawa et al., 1985).

Recently, there have been three reports that in the same patient with Graves' disease that both TSAb and TBII were evidenced during the hyperthyroid state, and that 
both TSBI and TBII were seen in the hypothyroid state after ${ }^{131}$ I therapy (Bech et al., 1982) and after anti-thyroid drug therapy as well (Kasagi et al., 1986; Tamai et al., 1987). The present report deals with a patient with Graves' disease who had TSAb and TBII before anti-thyroid drug therapy and then had TSBI and TBII when hypothyroidism developed during treatment. It would seem that TSBI can play a pathogenic role in hypothyroidism during or after treatment in a patient with Graves' disease. In order to rid this patient of TBII and TSBI, both high-dose intravenous gammaglobulin therapy and steroid therapy were attempted.

\section{Methods}

Serum $\mathrm{T}_{4}, \mathrm{~T}_{3}$, and TSH were measured by RIA using commercially available kits, and the normal ranges were found to be $5.9-12.3 \mu \mathrm{g} / \mathrm{dl}$, $118-214 \mathrm{ng} / \mathrm{dl}$, and less than $5.4 \mu \mathrm{U} / \mathrm{ml}$, respectively. Antithyroglobulin and antimicrosomal antibodies (TGHA and MCHA) were measured by a hemagglutination method, using a kit from the Fujizoki Co., Tokyo, Japan, and their normal ranges were shown to have a dilution factor smaller than 1 to 100 . TBII was determined by a radioreceptor assay using a kit purchased from S. R. S. Limited (Cardiff, UK) (Shewring and Smith, 1982), and its normal range was found to be $\pm 15 \%$, i.e., a positive reaction is above $15 \%$. IgG purified with DEAE-cellulose or DEAE-sephadex was used in the TSAb and TSBI assays. TSAb and TSBI were measured by using suspension cultured porcine thyroid follicles as described in other reports (Tamaru et al., 1985; Inomata et al., 1986). To determine the TSAb activity, $10 \mathrm{mg} / \mathrm{ml}$ of test IgG or control IgG was added to the suspension-cultured porcine thyroid follicles and, after incubation for $2 \mathrm{~h}$ at $37^{\circ} \mathrm{C}$, the cyclic-AMP in the resulting supernatant was measured. Positive TSAb activity was found to be above $160 \%$ ( $=+2 \mathrm{SD}$ of normal IgGs). To determine TSBI activity, $1 \mathrm{mU} / \mathrm{ml}$ of bovine TSH (Thytropar; Armour Pharmacentical Co., Phoenix, AZ) and $10 \mathrm{mg} / \mathrm{ml}$ of test IgG or control IgG were added to the thyroid follicles, and the resulting cyclic-AMP was measured. Positive TSBI activity was found to be below $51.5 \%$ (=-2SD of normal IgGs).

A $\mathrm{T}_{3}$ suppression test was performed by measuring the 24-hour thyroidal radio-activeiodine uptake (RAIU) after administering 75 $\mathrm{ug} /$ day of $\mathrm{T}_{3}$ for 7 days while taking maintenance doses of propyl-thiouracil (PTU). The $\mathrm{T}_{3}$ suppressibility is positive when the 24-h RAIU is less than 30\% (Sasaki et al., 1978).

\section{Case Reports}

\section{Present illness and laboratory finding}

In March 1980, a 12-year-old female suddenly suffered an attack of fever, arthralgia, and a scarlet fever-like erythema. Two weeks later, she was admitted to Kimitsu Chuo Hospital because of her fever and suspected tachycardia. Physical examination confirmed tachycardia (pulse rate : $110 / \mathrm{min}$.), finger tremor, struma, exophthalmos and petechia. Laboratory findings revealed that the white blood count, the red blood count, the hemoglobin, the hematocrit and the platelet count were $4,000 / \mathrm{mm}^{3}, 417 \times 10^{4} \mathrm{lmm}^{3}, 10.7 \mathrm{~g} / \mathrm{dl}, 34.5 \%$ and $45,000 / \mathrm{mm}^{3}$, respectively. The basal metabolic rate was $+16 \%$, the serum $\mathrm{T}_{4}$ was $14.6-16.1 \mu \mathrm{g} / \mathrm{dl}$, and the $\mathrm{T}_{3}$ was 289 $329 \mathrm{ng} / \mathrm{dl}$. TSH was not detected before or after TRH stimulation. The patient's TGHA was negative and her MCHA was strongly positive $(1: 102,400)$. GOT, GPT, and cholesterol were 13, $12 \mathrm{IU} / \mathrm{L}$ and $109 \mathrm{mg} / \mathrm{dl}$, respectively. IgG, A, and $M$ were 1793 , 140 , and $142 \mathrm{mg} / \mathrm{dl}$. ASLO was found to be 625 Todd units, the rheumatoid factor was negative, the anti-nucleolar antibody was weakly positive $(\times 20)$, the anti-DNA antibody was negative, and the LE test was negative. Examination of bone marrow showed $382,000 / \mathrm{mm}^{3}$ of nucleated cells, increased megakaryocytes $\left(272 / \mathrm{mm}^{3}\right)$, and no abnormal cells.

A few days after admission, a holosystolic 
cardiac murmur developed in the apex region. A diagnosis was made of Graves' disease, combined with idiopathic thrombocytopenic purpura (ITP), and a mitral valve insufficiency due to rheumatic fever. The patient was sent to Chiba University Hospital and treated with penicillin and prednisolone, after which her symptoms subsided and her platelet count normalized immediately. Prophylactic doses of penicillin had been administered to this point. Steroid therapy was continued for one month and then tapered off. The patient's platelet count maintained a normal range after steroid treatment. Her cardiac murmur continued after steroid therapy, but finally disappeared 4 years later.

\section{Family history}

The patient's mother had had Graves' disease at the age of 37 years and had been treated with an anti-thyroid drug for 4 years. In February 1985, 5 years after discontinuance of therapy, her mother was still euthyroid but had no TBII. No other members of the patient's family or close relatives have any history of autoimmune disorders or collagen diseases.

\section{The patient's clinical course}

The results of therapy for Graves' disease in this patient are shown in the Figure. PTU therapy was started in doses of 350 $\mathrm{mg}(10 \mathrm{mg} / \mathrm{kg})$ daily while prednisolone was tapered off. One month later, the patient's serum $\mathrm{T}_{4}$ and $\mathrm{T}_{3}$ returned to within the normal range. In August 1982, RAIU showed $14.6 \%$ after $\mathrm{T}_{3}$ administration during maintenance therapy with $100 \mathrm{mg}$ of PTU. Because positive $T_{3}$ suppressibility had been obtained, anti-thyroid drug therapy was discontinued.

Nine months after discontinuance of antithyroid drug, $\mathrm{T}_{4}$ and $\mathrm{T}_{3}$ increased to $14.9 \mu \mathrm{g} / \mathrm{dl}$ and $373 \mathrm{ng} / \mathrm{dl}$, respectively, and tachycardia developed. Treatment with PTU was therefore started again.

Eleven months after the start of this second treatment, the patient's serum $\mathrm{T}_{4}$ and $\mathrm{T}_{3}$ became subnormal, her TSH increased,

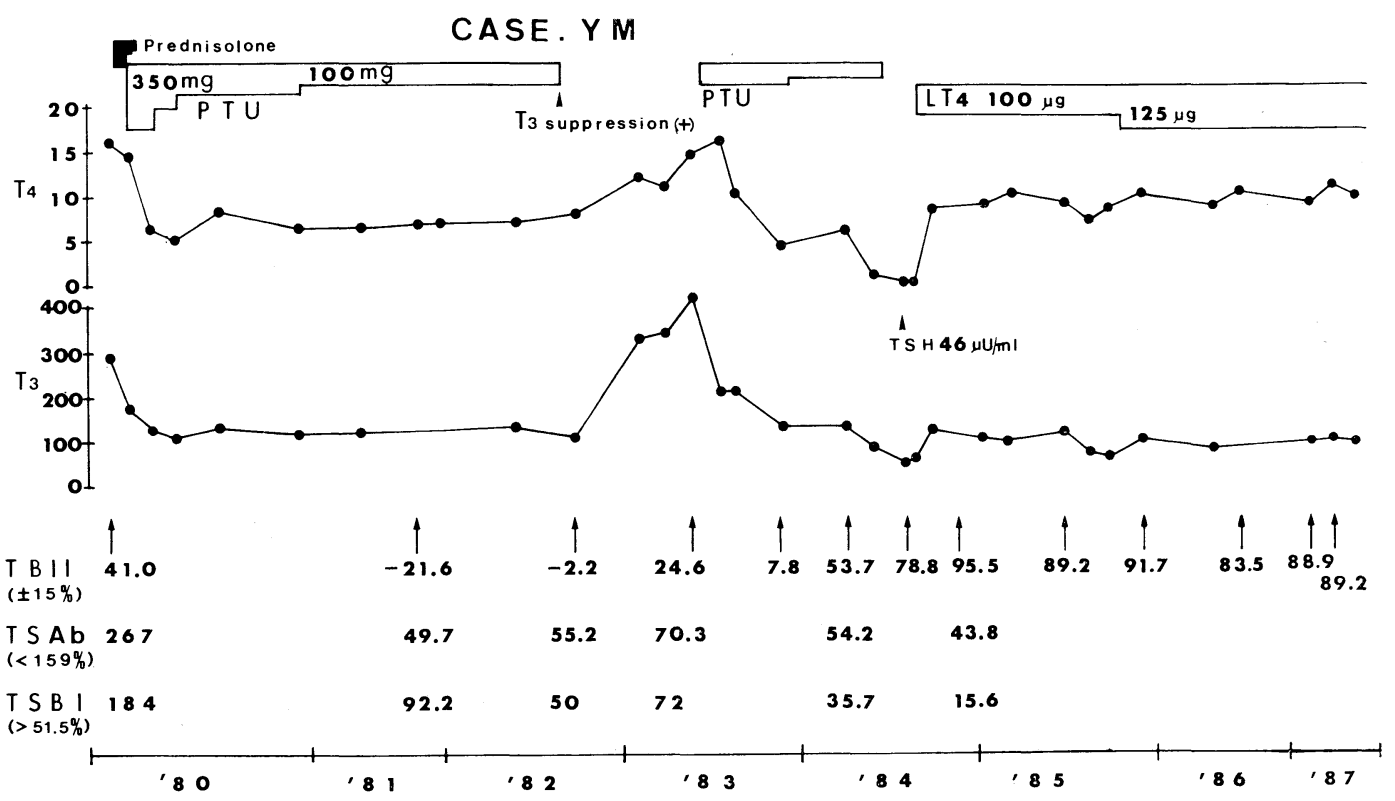


and she suffered from constipation. In spite of the discontinuance of PTU, her hypothyroidism continued. She was then treated with 1-thyroxine and became euthyroid. The maximal width of the thyroid was $6 \mathrm{~cm}$ at onset of Graves' disease, $4 \mathrm{~cm}$ at remission and not palpable when hypothyroidism developed.

The results of TBII, TSAb and TSBI

At the onset of Graves' disease, TBII (41.0\%) and TSAb (267\%) were positive. During the remission stage, TBII $(-2.2 \%)$ and $\mathrm{TSAb}(55.2 \%)$ became negative and TSBI $(50 \%)$ was weakly positive. At relapse, TBII $(24.6 \%)$ became weakly positive, but TSAb $(70.3 \%)$ and TSBI $(72 \%)$ were negative. When hypothyroidism developed, TBII (78.8\%) and TSBI (35.7$15.6 \%$ ) became positive.

\section{Cyclic- $A M P$ response in graded doses of IgG from the patient}

When the patient's IgG showed positive TSBI, TSAb activities of graded doses of her IgG were examined. No doses $(10,1.0$, $0.5,0.25,0.1,0.05$ and $0.01 \mathrm{mg} / \mathrm{ml}$ ) of her IgG displayed the characteristics of TSAb.

\section{The effects of high-dose intravenous gammaglobulin therapy or steroid therapy}

In March 1987, the patient was given $17.5 \mathrm{~g} \quad(370 \mathrm{mg} / \mathrm{kg})$ of gammaglobulin (Venilon ${ }^{\circledR}$ ) intravenously for 5 days, while undergoing maintenance therapy of 125 $\mu \mathrm{g} /$ day of $1-\mathrm{T}_{4}$. Her TBII concentration was $88.9 \%$ before therapy, and $75.2,88.8$ and $88.6 \%$ at 3 days, 1 month and 2 months after discontinuance of the therapy, respectively. TBII decreased slightly only at 3 days after therapy, but her thyroid function was unaffected during this study period.

In June 1987, she received $25 \mathrm{mg}(0.5$ $\mathrm{mg} / \mathrm{kg}$ ) of prednisolone for two weeks. Her TBII concentration was $88.6 \%$ before therapy, and 88.0 and $89.2 \%$ at 2 weeks and 4 weeks after initiation of the therapy, respectively. Furthermore, her thyroid function was unaffected throughout the study period.

\section{Discussion}

It has been reported that TBII and TSAb are positive in most patients with Graves' disease at the time of diagnosis, and that they affect the clinical outcome (McKenzie et al., 1978; Kasagi et al., 1986). Before the development of hypothyroidism in this patient, the changes in her TBII and TSAb reflected Graves' disease.

In a separate investigation, TBII with TSBI was found in patients with primary myxedema (Endo et al., 1978), and led to transient neonatal hypothyroidism by placental transmission (Matsuura et al., 1980; Inomata et al., 1986). When this patient developed hypothyroidism, her IgG showed characteristics of TBII and TSBI that were similar to IgG found in cases with primary myxedema.

The incidence of hypothyroidism after the cessation of anti-thyroid drug therapy is low in children with Graves' disease. In previous reports giving supporting stastistical data regarding the discontinuance of antithyroid drug therapy in children, none of 19 , none of 7 , none of 7,2 of 23 , none of 15 and 2 of 39 children developed hypothyroidism (Hung et al., 1962; Root et al., 1963 ; Mäenpää et al., 1966; Vaidya et al., 1974; Sasaki et al., 1978 ; and, Hamburger, 1985, respectively). In adults, a third of all such patients have evidenced partial or complete thyroid failure (Irvine et al., 1977). This fact has led Irvine et al. to speculate that thyroid failure is related to autoimmune processes of a destructive type.

In 1982 Bech et al. reported TSBI developing in the serum from two hypothyroid patients after ${ }^{131} \mathrm{I}$ therapy for Graves' disease. 
Kasagi et al. (1986) and Tamai et al. (1987) separately reported that a patient given anti-thyroid drug therapy developed hypothyroidism and was found to have TSBI. They both speculated that the emergence of TSBI after anti-thyroid drug treatment might be one of the factors responsible for the development of hypothyroidism in some patients with Graves' disease. The results obtained in this report support their speculation.

In 1983, Zakarija et al. reported on a patient with Hashimoto's disease who had TSBI and delivered a baby with a delayed onset of neonatal hyperthyroidism. At high concentrations, the character of their patient's IgG was TSBI, but at low levels it was TSAb. In our case, thyroid stimulation activity was not present at any dilution of IgG.

If the TSBI could have been eradicated, thyroid replacement therapy would not have been necessary in this patient. Moreover, in the future she would be able to avoid a hypothyroid fetus pregnancy and the delivery of a transiently hypothyroid neonate.

Further, high-dose intravenous gammaglobulin therapy has been found effective for cases of chronic thrombocytopenic purpura (Imbach et al., 1981), and there has been some speculation on the mechanism of the immunosuppresive effect, as well as on the inhibition of adsorption of the autoantibody to the target organ. Because it has been thought that TBII and TSBI are auto-antibodies to the thyroid membrane, gammaglobulin therapy might be effective for this patient. However, in this patient, the high-dose gammaglobulin therapy did not prove effective for her TBII and thyroid dysfunction. Mori et al. (1987) have reported on a patient with primary myxedema who showed positive TBII and TSBI during treatment with $0.5 \mathrm{mg}$ of betamethasone and whose TBII disappeared after about 5 months. They therefore speculated that steroids might be effective for TBII and dysthyroid function. In their case, however, doubts persist because the TSH, TBII and TSBI may not have been tested before their steroid therapy, and the TSBI was positive even when the TBII had disappeared. In our patient, $0.5 \mathrm{mg} / \mathrm{kg} /$ day of prednisolone for 2 weeks did not prove effective therapy for her TBII and thyroid dysfunction.

In conclusion, TSBI should be measured in hypothyroid patients with Graves' disease during and after anti-thyroid drug therapy, particularly since the emergence of TSBI might lead to hypothyroidism. Further studies are required on the production of biologicaly different IgGs related to the TSH receptor antibody in the same patient having Graves' disease, and an effective treatment for the disappearance of TBII and TSBI should be sought.

\section{References}

Arikawa, K., Y. Ichikawa, T. Yoshida, T. Shinozawa, M. Homma, N. Momotani and K. Ito (1985). Blocking type antithyrotropin receptor antibody in patients with nongoitrous hypothyroidism: Its incidence and characteristics of action. J. Clin. Endocrinol. Metab. 60, 953-959.

Bech, K., H. Bliddal, K. Siersbaek-Nielsen and T. Friis (1982). Production of non-stimulatory immunoglobulins that inhibit TSH binding in Graves' disease after radioiodine administration. Clin. Endocrinol. 17, 395-402.

Endo, K., K. Kasagi, J. Konoshi, K. Ikekubo, T. Okuno, Y. Takeda, T. Mori and K. Torizuka (1978). Detection and properties of TSH-binding inhibitor immunoglobulins in patients with Graves' disease and Hashimoto's thyroiditis. J. Clin. Endocrinol. Metab. 46, 734-739.

Hamburger, J. I. (1985). Management of hyperthyroidism in children and adolescents. $J$. Clin. Endocrinol. Metab. 60, 1019-1024.

Hung, W., L. Wilkins and R. Blizzard (1962). Medical therapy of thyrotoxicosis in children. Pediatrics 30, 17-26.

Imbach, P., S. Barandun, V. d'Apuzzo, C. 
Baumgartner, A. Hirt, A. Morell, E. Rossi, M. Schoni, M. Vest and H. P. Wagner (1981). High-dose intravenous gammaglobulin for idiopathic thrombocytopenic purpura in childhood. Lancet ii, 1228-1231.

Inomata, H., N. Sasaki, K. Tamaru, H. Ushiku, H. Niimi and H. Nakajima (1986). Relationship between potency of blocking type thyrotropin-binding inhibitor immunoglobulin in three women with primary myxedema and thyroid function of their neonates. Endocrinol. Japon. 33, 353-359.

Irvine, W. J., R. S. Gray, A. D. Toft, J. Seth, G. P. Lidgard and E. H. D. Cameron (1977). Spectrum of thyroid function in patients remaining in remission after antithyroid drug therapy for thyrotoxicosis. Lancet 2, 179-181.

Kasagi, K., Y. Iida, J. Konoshi, T. Misaki, K. Arai, K. Endo, K. Torizuka and K. Kuma (1986). Paired determination of thyroid-stimulating and TSH-binding inhibitory activities in patients with Graves' disease during antithyroid drug treatment. Acta Endocrinol. 111, 474480.

Konishi, J., Y. Iida, K. Endo, T. Misaki, Y. Nohara, N. Matsuura, T. Mori and K. Torizuka (1983). Inhibition of thyrotropininduced adenosine $3^{\prime} 5^{\prime}$-monophosphate increase by immunoglobulins from patients with primary myxedema. J. Clin. Endocrinol. Metab. 57, 544-549.

Mäenpää, J., H. Hiekkala and B. -A. Lamberg (1966). Childhood hyperthyroidism: Report on 39 cases. Acta Endoclinol. 51, 321-336.

Matsuura, N., Y. Yamada, Y. Nohara, J. Konishi, K. Endo, K. Kojima and K. Wataya (1980). Familial neonatal transient hypothyroidism due to maternal TSH-binding inhibitor immunoglobulins. N. Engl. J. Med. 303, 738741.

McKenzie, J. M. and M. Zakarija (1976). A reconsideration of a thyroid-stimulating immunoglobulin as the cause of hyperthyroidism in Graves' disease. J. Clin. Endocrinol. Metab. 42, 778-781.

Mori, T., T. Akamizu, S. Kosugi, D. Inoue,
M. Miyamoto, H. Sugawa, K. Kasagi, J. Konishi and H. Imura (1987). Disappearance of blocking type thyrotropin binding inhibitor immunoglobulin (TBII) during thyroid and steroid medication in a patient with autoimmune thyroiditis. Endocrinol. Japon. 34, 237244.

Root, A. W., A. M. Bongiovanni, F. H. Harvie and W. R. Eberlein (1963). Treatment of juvenile thyrotoxicosis. J. Pediatr. 63, 402407.

Sasaki, N., Y. Nakamura, H. Niimi and H. Nakajima (1978). Antithyroid drug therapy :T3 suppression test as an index for discontinuation of therapy. Shounika Rinshou 31, 1655-1660. (In Japanese).

Shewring, G. and B. R. Smith (1982). An improved radioreceptor assay for $\mathrm{TSH}$ receptor antibodies. Clin. Endocrinol. 17, 409-417.

Smith, B. R. and R. Hall (1974). Thyroidstimulating immunoglobulins in Graves' disease. Lancet, 2, 427-431.

Tamai, H., Y. Hirota, K. Kasagi, S. Matsubayashi, K. Kuma, Y. Iida, J. Konishi, M. C. Okimura, R. M. Walter, L. F. Kumagai and S. Nagataki (1987). The mechanism of spontanous hypothyroidism in patients with Graves' disease after antithyroid drug treatment. $J$. Clin. Endocrinol. Metab. 64, 718-722.

Tamaru, K., N. Sasaki, H. Inomata, T. Yasuda, H. Niimi and H. Nakajima (1985). Thyroidstimulating and thyrotropin-binding inhibitory activity of immunoglobulin from patients with thyroid disorder using suspension culture with porcine thyroid follicles. Horumon to Rinshou 33, 417-420. (In Japanese).

Vaidya, V. A., A. M. Bongiovanni, J. S. Parks, A. Tenore and R. T. Kirkland (1974). Twentytwo years' experience in the medical management of juvenile thyrotoxicosis. Pediatrics 54, 565-570.

Zakarija, M., L. M. McKenzie and D. S. Munro (1983). Immunoglobulin $G$ inhibitor of thyroid-stimulating antibody is a cause of delay in the onset of neonatal Graves' disease. J. Clin. Invest. 72, 1352-1356. 